Original Article

Artigo Original

Milene Rossi Pereira Barbosa ${ }^{1}$

Fernanda Dreux Miranda Fernandes ${ }^{1}$

Keywords

Autistic disorder

Diagnosis, differential

Behavior

Language

Descritores

Transtorno autístico Diagnóstico diferencial

Comportamento

Linguagem

Correspondence address:

Milene Rossi Pereira Barbosa

Rua dos Pinheiros, 405, Jardim Novo Mundo, Jundiaí (SP), Brasil, CEP: 13211-621.

E-mail: milenefono@yahoo.com.br

Received: 10/30/2013

\section{Comparing the results of DAADD and $A B C$ of children included in Autism Spectrum Disorders}

\author{
Comparação entre os resultados dos protocolos DAADD e ABC \\ de crianças incluídas nos Distúrbios do Espectro do Autismo
}

\begin{abstract}
Purpose: To verify if there are characteristic behaviors of the different diagnosis included in the autism spectrum according to the Differential Assessment of Autism and Other Developmental Disorders (DAADD) and to the Autism Behavior Checklist (ABC). Method: Participants were 45 individuals and their respective speech-language therapists. All therapists are graduate students working with the children for at least 1 year. This time was considered sufficient to the therapists to have the information required by the DAADD questionnaire. It is comprised by 3 protocols specifically designed to children with 2 to 4 years, 4 to 6 years and 6 to 8 years, the same criteria used to separate the research groups, G1, G2 and G3, respectively. Data referring to the $\mathrm{ABC}$ were retrieved from the subject's files at the Laboratório de Investigação Fonoaudiológica nos Distúrbios do Espectro do Autismo (Research Laboratory on Language Disorders in the Autism Spectrum) of the School of Medicine, Universidade de São Paulo, where it is routinely applied during the annual assessment. Results: Answers to the different areas of DAADD are similar to the different areas of ABC. These data show data the diagnosis by DAADD is easier in older children. Although there is no significant difference, the large occurrence of Rett's syndrome diagnosis according to the DAADD was associated to higher risk for autism according to the $\mathrm{ABC}$ in G1. With increasing age this tendency decreases and either in G2 and G3 Autism is the most frequent diagnosis. Conclusion: Although the results of both questionnaires tend to agree more with increasing age, the DAADD is more sensitive in the different ages while the $\mathrm{ABC}$ if more specific only to older children.
\end{abstract}

\section{RESUMO}

Objetivo: Verificar a existência de comportamentos característicos de diferentes quadros incluídos nos Distúrbios do Espectro do Autismo identificados segundo o Differential Assessment of Autism and Other Developmental Disorders (DAADD) e a Autism Behavior Checklist (ABC). Método: Participaram desta pesquisa 45 indivíduos autistas e suas respectivas terapeutas. Todas as terapeutas são fonoaudiólogas pós-graduandas e atendiam os sujeitos há pelo menos um ano, tempo considerado suficiente para fornecer as informações solicitadas pelo DAADD. Ele é composto por três protocolos especificamente dirigidos a crianças entre dois e quatro anos de idade, quatro e seis anos, e seis e oito anos, o mesmo critério usado para dividir os grupos da pesquisa em G1, G2 e G3, respectivamente. Os dados referentes à $\mathrm{ABC}$ foram retirados dos protocolos dos sujeitos, registrados no acervo do Laboratório de Investigação Fonoaudiológica nos Distúrbios do Espectro do Autismo da Faculdade de Medicina da Universidade de São Paulo, uma vez que ele é regularmente aplicado a todos os pacientes durante o processo de avaliação anual. Resultados: As respostas do DAADD, por área, se aproximam das respostas do ABC, também por área. Os dados evidenciam que, conforme a idade aumenta, é mais fácil identificar o diagnóstico pelo DAADD. Apesar de não haver diferença estatisticamente significativa, a grande ocorrência do diagnóstico de SR obtida no DAADD associou-se à alta probabilidade no $\mathrm{ABC}$ para o G1. Conforme aumenta a idade, essa prevalência diminui, sendo o autismo mais prevalente no item alta probabilidade tanto para o G2 quanto para o G3. Conclusão: Apesar de os protocolos serem mais concordantes conforme aumentam as idades, por faixa etária, o DAADD se mostra mais sensível, enquanto o ABC é mais específico apenas para as crianças mais velhas.

Study carried out at the Physical Therapy, Speech Language and Audiology and Occupational Therapy Department in the School of Medicine, Universidade de São Paulo - USP - São Paulo (SP), Brazil.

(1) School of Medicine, Universidade de São Paulo - USP - São Paulo (SP), Brazil. Financial support: National Council for Scientific and Technological Development (CNPQ). Conflict of interests: nothing to declare. 


\section{INTRODUCTION}

In the past decades, the speech language and audiology therapeutic intervention has been emphasized as a way of socially adapting the communicative behavior, thus leading to improvements in the inclusion of children with autism in their social environment ${ }^{(1,2)}$

Because autism was no longer considered to be a psycho$\operatorname{sis}^{(3)}$, it began to be analyzed as a pervasive developmental disorder, and authors who study it try to define diagnostic criteria by observing and describing the cases clinically, thus providing behavioral and psychological characteristics that are observed in the children. From these behavioral aspects, it was possible to classify its severity and elaborate several measuring instruments or evaluation scales ${ }^{(4,5)}$.

The concept of autism spectrum disorders (ASD) has been proposed to include the different global developmental disorders into an articulated perspective, which involves the complex interrelationship between the several clinical pictures ${ }^{(6)}$. This does not rule out the need to conduct differential diagnosis between these pictures, as suggested by some authors. According to them ${ }^{(7)}$, the typical disorder, autism, would be at the center of a circle, whereas the others would become more distant according to the decreasing severity of symptoms and number of affected sites. Besides, other criteria are suggested to distinguish the disorders included in the autism spectrum, such as the onset of symptoms, the presence or absence of mental retardation, severity of symptoms, and qualitative characterization of the affected areas ${ }^{(8)}$.

Facing such a complex situation, by observing and diagnosing these children, it is possible to observe the need to use screening instruments for behavioral issues, which would lead to more rigid observation and behavioral records ${ }^{(4-9)}$.

The Autism Behavior Checklist $(\mathrm{ABC})^{(10)}$ is a scale used for nonadaptive behaviors created to screen and indicate the probability of a diagnosis of autism. The questionnaire approaches 57 atypical behaviors related to five areas: sensorial, relational, use of body and objects, and social skills. The identified behavioral scores are accounted by area, which lead to the general score.

However, there is no unanimity as to the values indicated in this proposal. They are considered to be too high, and tend not to classify an important portion of children ${ }^{(11)}$.

It is mainly important to point out that nonverbal children do not score in the items referring to expressive language, in the language subscale, and this represents important bias for the diagnosis. The situation led several authors ${ }^{(12)}$ to consider the ABC to be a highly specific scale, that is, which does not include individuals without autism; however, its sensitivity is low, because it tends not to include many individuals with autism.

The Differential Assessment of Autism and Other Developmental Disorders (DAADD) ${ }^{(13)}$ was created to discriminate, by identifying the behavior of children, specific developmental disorders, such as autism, Rett syndrome (RS), Asperger syndrome (AS), pervasive developmental disorders not otherwise specified (PDD-NOS), apraxia, mental retardation (MR), and other syndromes (OS). The last three categories will not be approached in this study because they are not part of the PDD, according to the Diagnostic and Statistical Manual of Mental Disorders (DSM-IV-TR) ${ }^{(14)}$ or according to the International Classification of Diseases (ICD 10) ${ }^{(15)}$.

The DAADD ${ }^{(13)}$ is an assessment instrument composed of three protocols addressed to children aged between two and four years old, 4-6 years, and 6-8 years old, which analyzes six developmental areas: language, pragmatics, sensorial, motor, physical, and behavioral.

Literature identifies these areas as being adequate for the differentiation and diagnosis of neurological disorders ${ }^{(13)}$. The focused questions are frequently observed among children with developmental disorders.

The objective of this study was to verify the existence of characteristic behaviors of different pictures included in the ASD, identified according to the DAADD ${ }^{(13)}$ and the $\mathrm{ABC}^{(10)}$.

Specific objectives are to verify the efficacy of the DAADD for the diagnosis in the autism spectrum by comparing the results presented by the $\mathrm{ABC}$ for the same population and by comparing the occurrence of behaviors presented by the assessed population according to the developmental areas analyzed by both protocols.

\section{METHODS}

The study was approved by the research ethics committee of Hospital das Clínicas, in the School of Medicine of Universidade de São Paulo (FMUSP) (protocol number 364/10). Parents or people in charge of the participants signed the informed consent.

Forty-five individuals and their respective pathologists participated in this study. All of the assessed individuals attended therapy sessions in the Research Laboratory on Language Disorders in the Autism Spectrum (LIF-DEA), at FMUSP, and their diagnoses were included in the ASD, attributed by neurologists and/or psychiatrists according to criteria from the DSM-IV (2002) or ICD-10 (2003).

By following the orientations to apply the instrument, which is composed of three protocols addressed to children aged 2-4 years, $4-6$ years, and 6-8 years, Figure 1 shows the characterization of individuals according to age. They were divided into three groups, each group with 15 children, without considering the schooling level or family income as inclusion criteria. The first group (G1) comprised children aged between 2 and 4 years, the second one (G2) had children aged between 4 and 6 years, and the third one (G3) had children aged between 6 and 8 years.

Of the 45 participants assessed, 29 had been diagnosed with autism, 7 with global developmental disorder, 5 with PDDNOS, 2 with AS, 1 with high-functioning autism, and 1 with atypical autism.

Since this instrument is extensive and detailed, with technical data, the application of DAADD ${ }^{(13)}$ was conducted by interviews with the therapists in charge of each one of the 45 individuals. All speech language pathologists are postgraduate students who had been assisting the participants for at least 1 year, and this period was considered to be sufficient for the therapists to provide the proper information requested by the DAADD ${ }^{(13)}$. 


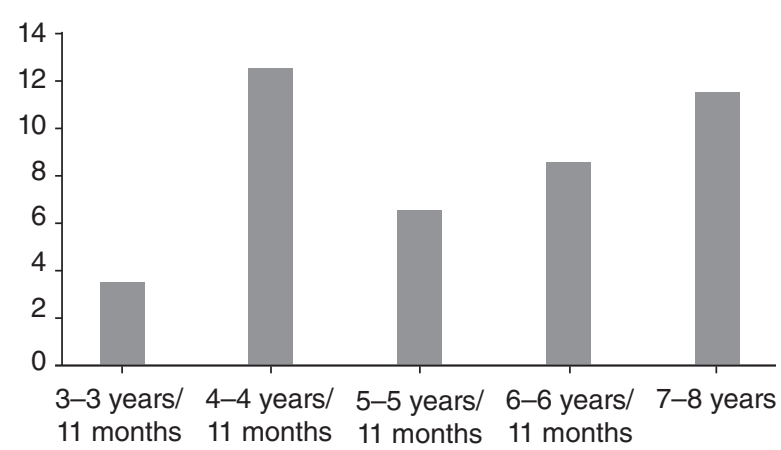

Figure 1. Characterization of subjects with relation to age

The data referring to the $\mathrm{ABC}^{(10)}$ were taken from protocols of the participants registered in the LIF-DEA records, at FMUSP, once it is regularly applied to all of the patients during the annual assessment process. The data obtained from the two evaluations were analyzed by individual, verifying the global development based on individual comparison.

Information in the $\mathrm{ABC}^{(10)}$ and the $\mathrm{DAADD}^{(13)}$ were related according to the categories presented in Chart 1.

The data obtained in both instruments were compared. The adopted significance level was 0.05 (5\%), and significant areas were analyzed with the Student's $t$-test.

The Wilcoxon Signed-Rank test was conducted to verify linear correlations between the analyzed areas in both instruments.

\section{RESULTS}

Figure 2 shows the classification of probability for autism according to the $\mathrm{ABC}$ of the analyzed population. The $\mathrm{ABC}$ assessment protocol does not consider the existence of a spectrum, because it was created much prior to this notion.

It is possible to observe that among older children, $20 \%$ are identified by the $\mathrm{ABC}$ as "no risk for autism".

Table 1 presents higher occurrence of responses in the DAADD according to the investigated developmental disorders. It is possible to notice that both $\mathrm{G} 2$ and $\mathrm{G} 3$ presented more diagnoses of autism, and these groups had only two variations of the disorders, whereas G1 presented all of the possible variations.

By comparing the DAADD with the conclusion from the $\mathrm{ABC}$, it is possible to observe that even though there is no statistically significant difference, the large number of RS diagnoses by the DAADD through the several motor questions included in the instrument was more prevalent in the high probability item in the $\mathrm{ABC}$ for $\mathrm{G} 1$.

With age, this prevalence declines, and autism becomes more prevalent in the high probability item both for G2 and G3. This information is reinforced because the large number of AS diagnoses in $\mathrm{G} 3$ (75\% of the total) is defined as high probability for autism in the $\mathrm{ABC}$.

With the objective of comparing the responses obtained in the areas approached by the $\mathrm{ABC}$ and those analyzed in the DAADD, the Wilcoxon Signed-Rank test was used.
Chart 1. Matching the areas of the instruments Autism Behavior Checklist and Differential Assessment of Autism and Other Developmental Disorders

\begin{tabular}{|lc|}
\hline Autism Behavior Checklist & $\begin{array}{c}\text { Differential Assessment of } \\
\text { Autism and Other Developmental } \\
\text { Disorders }\end{array}$ \\
\hline Language & Language \\
Relational & Pragmatics \\
Sensorial & Sensorial \\
Use of body and object & Motor \\
Social skills & Behavioral \\
\hline
\end{tabular}

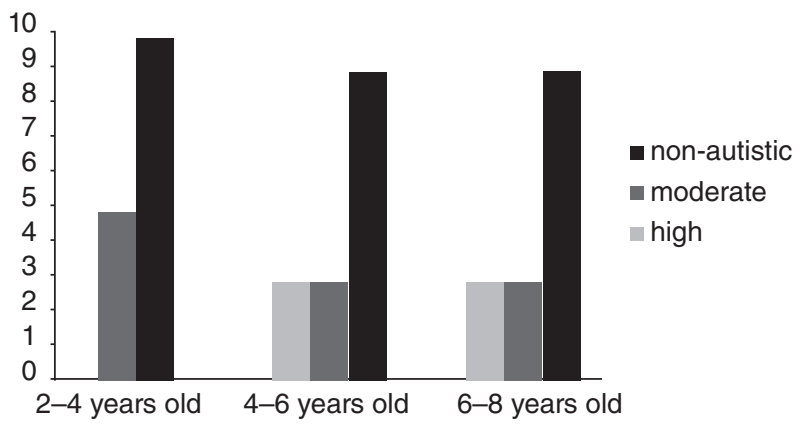

Figure 2. Probability of autism according to the Autism Behavior Checklist

Table 1. Occurrence of responses in the Differential Assessment of Autism and Other Developmental Disorders according to developmental disorders

\begin{tabular}{lcc}
\hline Groups & Diagnosis & Number of occurrences \\
\hline \multirow{3}{*}{ G1 } & Autism & 4 \\
& Rett syndrome & 9 \\
& Asperger syndrome & 2 \\
\hline \multirow{2}{*}{ G2 } & Autism & 13 \\
& Rett syndrome & 2 \\
\hline \multirow{2}{*}{ G3 } & Autism & 10 \\
& Asperger syndrome & 5 \\
\hline
\end{tabular}

The respective areas were separately related by age, according to Tables 2 to 4.

Responses in the DAADD by area are close to those in the $\mathrm{ABC}$ also by area. Data show that it becomes easier to identify the diagnosis in the DAADD with age.

Even though protocols agree more with increasing age, the DAADD has proven to be more sensitive for different age groups, whereas the $\mathrm{ABC}$ is more specific, addressed to older children.

The $\mathrm{ABC}$ has only one diagnostic probability, whereas the DAADD distinguishes the already diagnosed child in the possibilities of the autism spectrum, and some disorders that are not included in it.

\section{CONCLUSION}

For several authors ${ }^{(1,2)}$, speech language and audiology therapeutic intervention has been emphasized as a manner of 
Table 2. Comparison between the areas of the Differential Assessment of Autism and Other Developmental Disorders and the Autism Behavior Checklist for G1

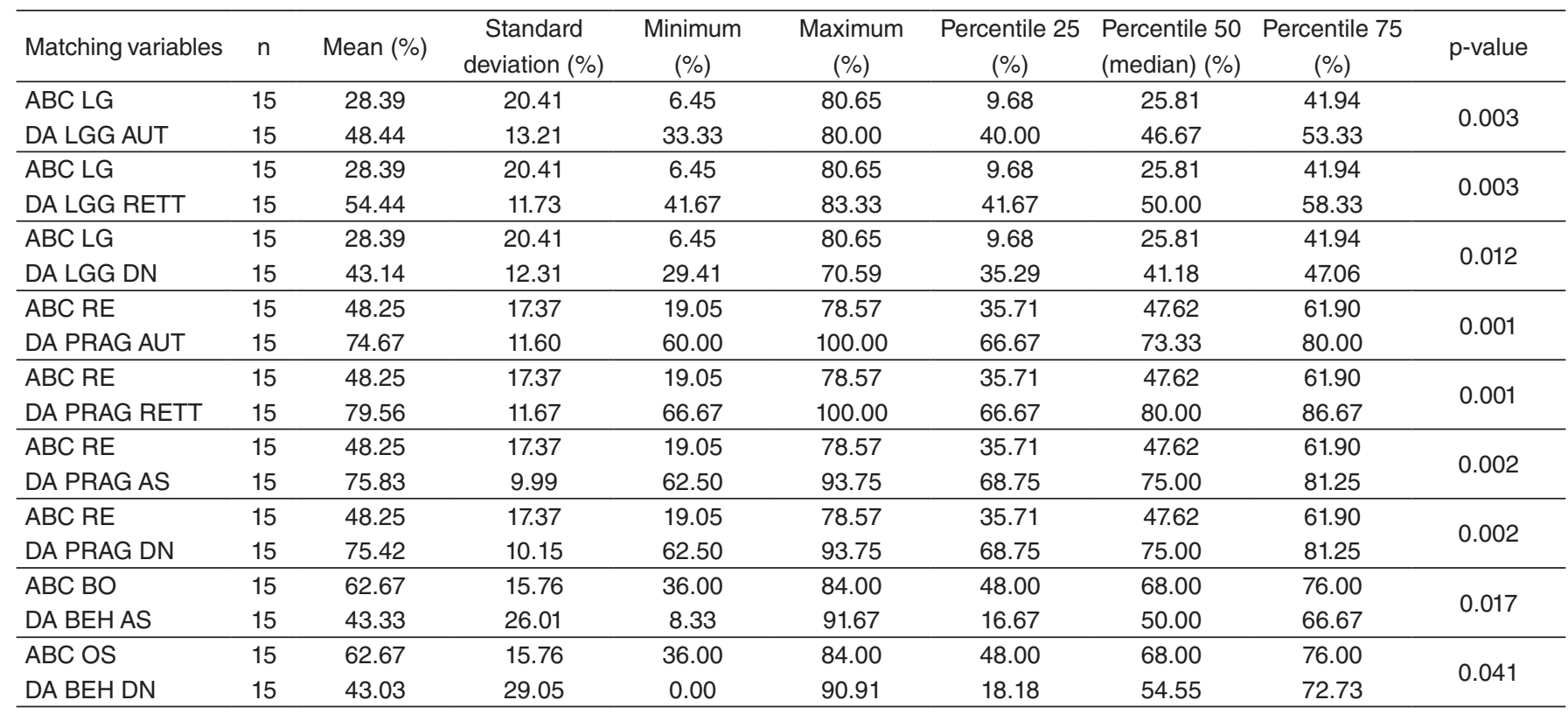

Caption: $A B C=$ Autism Behavior Checklist; $L G=$ language; $D A=$ Differential Assessment of Autism and Other Developmental Disorders; $L G G=$ language; $A U T=$ autism;

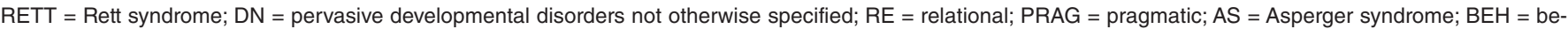
havioral; $\mathrm{BO}=$ use of body and objects

Table 3. Comparison between the areas of the Differential Assessment of Autism and Other Developmental Disorders and the Autism Behavior Checklist for G2

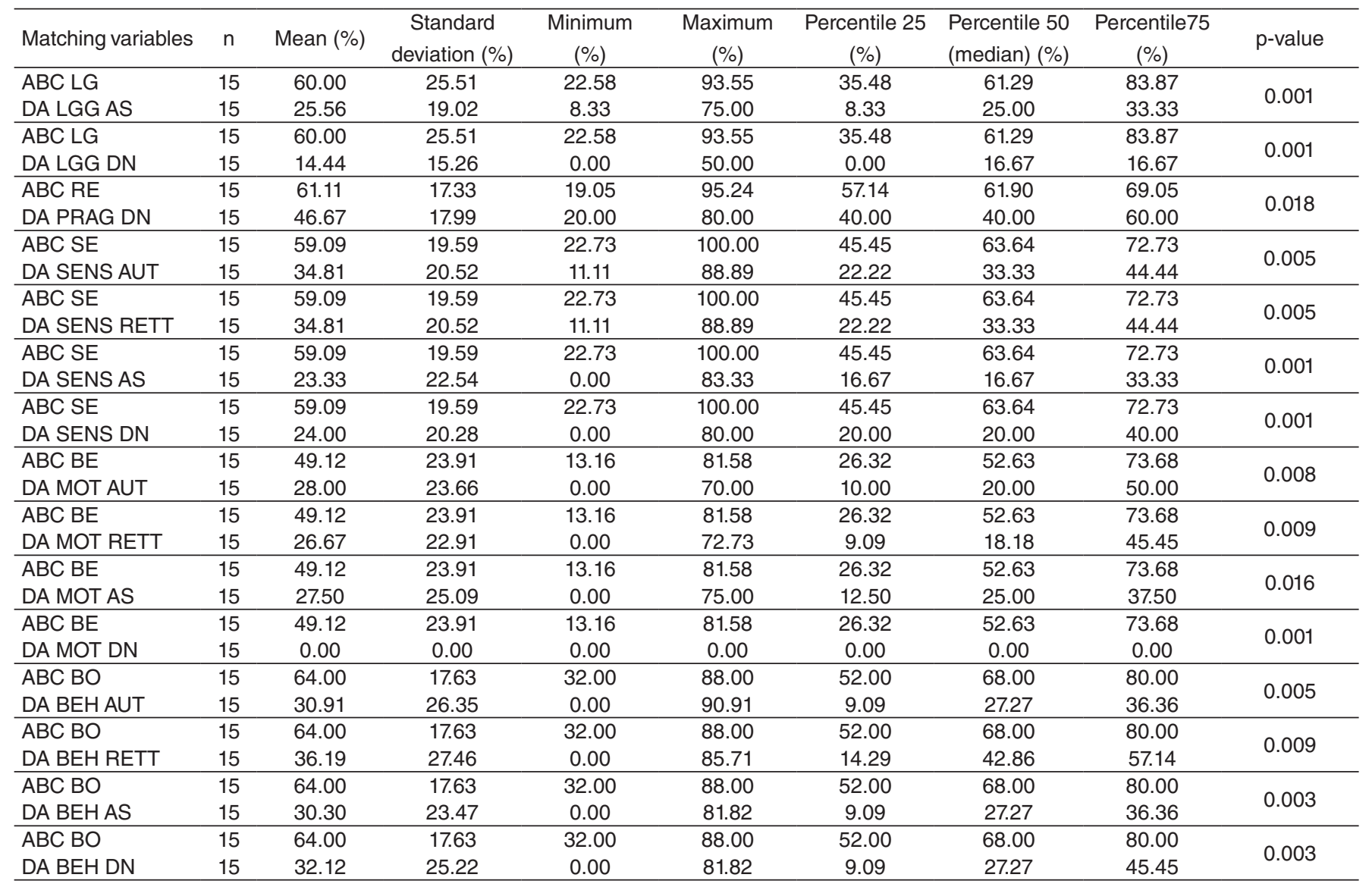

Caption: $\mathrm{ABC}=$ Autism Behavior Checklist; $\mathrm{LG}=$ language; $\mathrm{DA}=$ Differential Assessment of Autism and Other Developmental Disorders; $\mathrm{LGG}=$ language; $\mathrm{AS}=\mathrm{Asperger}$ syndrome; $\mathrm{DN}=$ pervasive developmental disorders not otherwise specified; $\mathrm{RE}=$ relational; $\mathrm{PRAG}=$ pragmatic; $\mathrm{SE}=$ sensorial; $\mathrm{SENS}=$ sensorial; $\mathrm{AUT}=\mathrm{autism}$; $\mathrm{RETT}=$ Rett syndrome; $\mathrm{BE}=$ behavioral; $\mathrm{MOT}=$ motor $; \mathrm{BO}=$ use of body and object; $\mathrm{BEH}=$ behavioral 
Table 3. Comparison between the areas of the Differential Assessment of Autism and Other Developmental Disorders and the Autism Behavior Checklist for G3

\begin{tabular}{|c|c|c|c|c|c|c|c|c|c|}
\hline Matching variables & $\mathrm{n}$ & Mean (\%) & $\begin{array}{c}\text { Standard } \\
\text { deviation (\%) }\end{array}$ & $\begin{array}{c}\text { Minimum } \\
(\%)\end{array}$ & $\begin{array}{c}\text { Maximum } \\
(\%)\end{array}$ & $\begin{array}{c}\text { Percentile } 25 \\
(\%)\end{array}$ & $\begin{array}{l}\text { Percentile } 50 \\
\text { (median) (\%) }\end{array}$ & $\begin{array}{c}\text { Percentile } 75 \\
(\%)\end{array}$ & $p$-value \\
\hline ABC SE & 15 & 43.94 & 21.37 & 0.00 & 77.27 & 31.82 & 45.45 & 59.09 & 0.030 \\
\hline ABC SE & 15 & 43.94 & 21.37 & 0.00 & 77.27 & 31.82 & 45.45 & 59.09 & \multirow{2}{*}{0.020} \\
\hline DA SENS DN & 15 & 13.33 & 35.19 & 0.00 & 100.00 & 0.00 & 0.00 & 0.00 & \\
\hline
\end{tabular}

Caption: $\mathrm{ABC}=$ Autism Behavior Checklist; SE = sensorial; DA = Differential Assessment of Autism and Other Developmental Disorders; SENS = sensorial; $\mathrm{AS}=$ Asperger syndrome; $\mathrm{DN}=$ pervasive developmental disorders not otherwise specified; $\mathrm{BE}=$ behavioral; $\mathrm{MOT}=\mathrm{motor}$

social adaptation of the communicative behavior of the individuals included in the autism spectrum, thus enabling to better include the children with autism in their social environment.

From observing and diagnosing these children, the need to use screening instruments for behavioral issues is necessary, because they can make observation and behavioral records stricter ${ }^{(4-9)}$.

After associating both instruments (ABC and DAADD), we observed that, for $\mathrm{G} 2$ and $\mathrm{G} 3$, the higher the probability in the $\mathrm{ABC}$ for the diagnosis of autism spectrum, the higher the number of diagnoses in the autism spectrum in the DAADD, which indicates that the difficulty found in the ABC for diagnosis is not found in the DAADD. Because all of the individuals in this study belong to the ASD, the use of protocols may favor the differentiation, and not only assist with the diagnosis.

Finally, the complementary use of two instruments is recommended, because the ABC only brings one diagnostic probability, whereas the DAADD distinguishes the already diagnosed child among the possibilities within the autism spectrum, and some that are not included in it.

*MRPB was in charge of data collection and tabulation, as well as treatment of data and literature review; FDMF collaborated with the study design, oriented data analysis, and the discussion of results.

\section{REFERENCES}

1. Tamanaha AC, Perissinoto J, Chiari BM. Evolução da criança autista em diferentes contextos de intervenção a partir das respostas das mães ao Autism Behavior Checklist. Pró-Fono R Atual Cient. 2008;20(3):165-70.

2. Fernandes FD, Cardoso C, Sassi FC, Amato CH, Sousa-Morato PF. Fonoaudiologia e autismo: resultado de três diferentes modelos de terapia de linguagem. Pró-Fono R Atual Cient. 2008;20(4):267-72.
3. Ritvo ER, Ornitz EM. Autism: diagnosis, current research and management. New York: Spectrum; 1976.

4. Matson JL, Nebel-Schwalm M, Matson ML. A review of methodological issues in the differential diagnosis of autism spectrum disorders in children. Res Autism Spect Dis. 2007;1(1):38-54.

5. Reichow B, Volkmar FR. Social skills interventions for individuals with autism: evaluation for evidence-based practices within a best evidence synthesis framework. J Autism Dev Disord. 2010;40(2):149-66.

6. Fernandes FDM, Miilher LP. Relações entre a Autistic Behavior Checklist $(\mathrm{ABC})$ e o perfil funcional da comunicação no espectro autístico. Pró-Fono R Atual Cient. 2008;20(2):111-6.

7. Lord C, McGee JP. Educating children with autism. Washington, DC: National Academy Press; 2001.

8. Fernandes FDM, Molini-Avejonas DR, Sousa-Morato PF. Perfil funcional da comunicação nos distúrbios do espectro autístico. Rev CEFAC. 2006;8(1):20-6.

9. Posserud M, Lundervold AJ, Lie SA, Gillberg C. The prevalence of autism spectrum disorders: impact of diagnostic instrument and nonresponse bias. Soc Psychiatry Psychiatr Epidemiol. 2010;45(3):319-27.

10. Krug D, Arick J, Almond P. Autism Behavior Checklist - ABC. In: Krug DA, Arick J, Almond P (eds.). Autism Screening Instrument for Educational Planning- ASIEP-2. Austin, TX: PRO-ED; 1993.

11. Rellini E, Tortolani D, Trillo S, Carbone S, Montecchi F. Childhood Autism Rating Scale (CARS) and Autism Behavior Checklist (ABC) correspondence and conflicts with DSM-IV criteria in diagnosis of autism. J Autism Dev Disord. 2004;34(6):703-8.

12. Bildt A, Sytema S, Ketelaars C, Kraijer D, Muldre E, Volkmar F, et al. Interrelationship between Autism Diagnostic Observation ScheduleGeneric (ADOS-G), Autism Diagnostic Interview-Revised (ADI-R), and the Diagnostic and Statistical Manual of Mental Disorders (DSM-IVTR) classification in children and adolescents with mental retardation. J Autism Develop Disord. 2004;24(2):129-37.

13. Gail JR, Lynn KC. Differential Assessment of Autism and Other Developmental Disorders (DAADD). East Moline, IL: LinguiSystems; 2003.

14. American Psychiatric Association Manual de diagnóstico e estatístico de distúrbios mentais DSM-III-R. 4ª ed. São Paulo: Manole; 2002.

15. Organização Mundial de Saúde. Classificação estatística internacional de doenças e problemas relacionados à saúde (CID-10). São Paulo: Universidade de São Paulo; 2003. 